\title{
An Empirical Study of the Factors influencing the effectiveness of Online Advertisement
}

\author{
SeemaWadhawan ${ }^{1}$, Sweety Gupta ${ }^{2}$, Shikha Dua $^{3}$ \\ ${ }^{1,2}$ (Research Scholar, Amity University, India) \\ ${ }^{3}$ (Assistant Professor, Rukmini Devi Institute of Advanced Studies, GGSIPU, India)
}

\begin{abstract}
With technological advancement being accessible easily, the field of online advertisement and EBusiness is definitely going to be the future in the shopping era. In today's world, in which we are living the information is flowing from all sources like television, advertising, films, videos, billboards, magazines, movies, music, newspaper, and internet. Analyzing the impact of immense opportunities which is being offered by internet, it is providing a new prospect to the industry of advertisement and marketing. The internet revolution is creating future endeavors for e-marketing over conventional marketing. The traditional ways included TV, radio, newspaper but they are now being replaced by modern way of advertisement that includes advertisement through E-mails, Google Ad sense and mobile messages. The present research paper has used Qualitative and Quantitative research methods. This research is a two-fold study where at one phase we would be able to explore the factors affecting online advertisement. At the other phase we would study the impact of factors influencing the effectiveness of online advertisement.
\end{abstract}

Keywords: online advertisement, social networking sites.

\section{INTRODUCTION}

Marketing is done in various ways, where advertising is such an important and irreplaceable technique which can have a long lasting impact on the minds of the consumers. In today's modern environment, advertising has become one of the major sources of marketing between buyer and seller. Advertising is the technique which is adopted by the retailers and the seller to reach out the customers at large and convert them to one of the potential customers. In this highly competitive environment and with revolution in the technology, right advertising medium and appropriateness of the advertising campaign can be one of the successful tools of the retailers. Advertising is such a technique of marketing and one element of promotion mix which is used for promoting the product in the eyes of the customers. Through this technique the business is successfully able to create the awareness of the product in the consumer's mind.

\subsection{CONCEPT OF ONLINE ADVERTISING}

With the technological advancement taking place and internet being accessible easily, online advertising is such a tool of marketing which is most current and real. Since Internet has become a communication platform, the frequent use of Internet advertising emerges naturally. Online advertising, which is based on Internet advertising, is a new medium with "the use of Internet and related digital technologies to achieve marketing objectives..." (Chaffey et al., 2006).This strategy of marketing involves the use of electronic means to get the website traffic to capture, target and deliver the message of marketing to the potential customer. In order to have maximum coverage and to reach customers at large online advertising is one of the effective tools, with availability of internet. Commonly known as web advertising or internet advertising, online advertising uses websites as their means to deliver their message to consumers. Adequate channel of advertising with a right campaign will become one of the success factors of the company in this competitive environment. Corporates with the adequate use of internet and high quality of their websites can attract huge traffic and achieve the objective of internet marketing. E-marketing however does not give this guaranty that the company will gain a competitive advantage in the market by choosing this technique of marketing and advertising. 
The biggest benefit of online advertising is the quick promotion of product information to the potential customer without geographical boundary limits. E-advertisements are purchased through one of the following three ways:

a. Cost per Thousand (CPM): In this method of advertisement, advertisers pay when their messages are exposed to specific number of audiences.

b. Cost per Click (CPC): In this method of advertisement, advertisers make payment every time a user clicks on their ads.

c. Cost per Action (CPA): In this method of advertisement, advertisers only pay when a specific action (generally a purchase) is performed.

Examples of online advertising include banner ads, search engine results pages, social networking ads, email spam, online classified ads, pop-ups, contextual ads and spyware.

\subsection{HISTORY OF ONLINE ADVERTISING}

With time, online advertisement has gone a sea change. When the Internet first came into the mainstream, and become accessible to everyone then there were many doubt about the viability of internet as a commercial medium. Internet was not accessible to a major portion of people and many early attempts at online advertising did not meet the standard performance. Additionally, the fact that advertisers and customers did not understand the online space well accounted for the fact that online advertisement didn't give the desired results. But with time as more and more Internet users acquired broadband connections, online advertisements have become very attractive. It resulted into advertisers experimenting with ads in the form of pop up in a new window, or pop up under the existing window so that the user would see the ad even after closing the main window. The fundamental behind this kind of advertising was to create advertisements in a manner that the user would be left with no choice but to look at the advertisement. This resulted in the user to give some attention to the advertisement or at least remember the message.

\subsection{OnLINE AdVERTISEMENT EFFECTIVENESS EVALUATION THEORIES}

Online advertising is audited by determinants like product or service recall, brand awareness, changes in the attitude of customer, the researches done earlier focus on such processes, integration of old theories with some new ones which are specific to online advertising(Ha 2008). It is claimed that the usefulness of online advertisements should be assessed by their ability to generate click-through, which refers to a user's clicking on a certain web advertisement, or some other behavioural responses, such as sales or interactions on a website (Bagherjeiran, Parekh 2008; Burns, Lutz 2006; Ghajarzadeh et al. 2010; Papadopoulos et al. 2009; Rodgers 2004). Others have claimed that straight response is a complex phenomenon which is partly determined by factors relating to the predisposition of the audience, not the advertising itself (Baltas 2003; Bruner II, Kumar 2000). One individual means cannot showcase a complex picture of online advertising. It is essential to consider the objectives of marketing in order to discuss and study the effectiveness of marketing. If the objective is to attract online users to visit its website, then the ability of advertisement to generate the desired behavioural responses should be measured, but if the objective is to increase brand awareness, the level of click may be irrelevant.

E-advertising is directly related with the specific aspect, (objective advertisement features) and the customer-specific aspect (subjective advertisement features) (Rodgers, Thorson 2000). Most of these factors include structural elements, such as advertisement features, formats and types. Factors that are specific to users, such as their personal propensities, perceptions, and motivation, may influence the effectiveness of online advertising as well.

Studies found that advertising on the web has sizable effects on brand loyalty and attitudes that can't be reflected in click-through (BergkvistMelander 2000; Bruner II, Kumar 2000). Howev- er, the internet introduces an additional dimen- sion - alienation (subject's estrangement from its community, society). 
More detailed analysis of advertising tools and researches in this field is essential in order to identify the online advertising efficiency factors.

\section{LiteratURE REVIEW}

A great number of researchers, like Tyagi and Kumar (2004), have explained the Topic of advertising management, from the perspective of advertisers. However, the authors study, focuses on how advertising management influences advertising effectiveness, in the context of online advertising.

Bezjizn-Avery, Calder. (1998), states that there are only two ways to measure the effectiveness of the interactive media. One of them is the persuasiveness of the media which states that consumers are positive in affect, preferences, and purchase intensions (Bezjizn-Avery etal, 1998). The research guides the ways to design effective online ads to capture the full advantages of the E-Advertising. Patsioura et al. (2009) have worked upon dvertising effectiveness model for corporate advertising web sites.

Teo, Wei. (2003) states in his research a model to study the influences of interactivity level on web user"s attitude towards commercial web sites. Internet advertising, which is a relatively new medium, has received attention from both academics and practitioners, particularly from effectiveness aspect.

Eighmey, Korgaonkar\&Wolin, 1997. States that attitude toward Internet advertising on the Web based environment has an impact on customers.

Schlosser, Shavitt\&Kanfer, 1999) states that some surveys conducted states that respondents sees that Eadvertising as more instructive and reliable than a demographically similar sample found in common advertising Ducoffe (1996) in his study argued that the distinction between advertising and web editorial is uncleared, with 57\% of respondents classifying web pages as advertising. This recommend that consumer give remarks about web advertising need to be construed carefully, because they may refer to the Internet pages themselves rather than to the advertisements they carry.

\section{RESEARCH METHODOLOGY}

\subsection{OBJECTIVES OF THE STUDY}

- To explore the factors affecting online advertisement.

- To study the impact of factors which influence the effectiveness of online advertisement.

3.2 METHOD OF THE STUDY: Exploratory \& Descriptive Study

- The Design: Exploratory \&Descriptive Research Design.

- The Sample

i. Sample Size: 150 respondents

ii. Sampling Procedure: It is not feasible to study all the employees of Delhi under this study therefore, convenient sampling will be used.

\subsection{FOR DATA COLLECTION}

Primary data through the standardised questionnaire will be collected and the Secondary data through reliable sources will be collected.

\subsection{SAMPLING TECHNIQUE}

Simple random sampling technique was used to gather data from the respondentsso that various respondents belonging to all age group, gender, professions, and religions could be covered but it was restricted to areas of Delhi/NCR.

3.5 STATISTICAL TOOLS USED

IBM SPSS 21.0 (Statistical Package for the Social Sciences), for data analysis which include regression analysis and for the reliability the Cronbach's Alpha was calculated and sample adequacy was tested on KMO and Bartlett's Test.

\subsection{ABOUt THE QUeSTIONNAIRE}


A self-constructed well-structured questionnaire is used for the collection of data. It is designed in such a manner to explore the effectiveness of Online Advertisements.

\subsection{LimitaTIONS OF THE STUDY}

As convenience sampling is used, all the non-probability errors would be there. Sample size is 150 respondents, it is not necessary that it truly represents the population/universe. Some people might not have given accurate responses, which affects the results of the study. Some respondents might have not taken the schedule seriously, and hence, few responses had to be discarded.

\subsection{HYPOTHESIS FORMULATION:}

\subsubsection{Hypothesis 1}

Ho1: There is no significant relationship between gender and effectiveness of Online Advertisement on Consumer's Purchasing Behavior.

Ha1: There is a significant relationship between gender and effectiveness of Online Advertisement on Consumer's Purchasing Behavior.

\subsubsection{Hypothesis2}

Ho2: There is no significant relationship between age and effectiveness of Online Advertisement on Consumer's Purchasing Behavior.

$\mathrm{Ha}$ 2: There is a significant relationship between age and effectiveness of Online Advertisement on Consumer's Purchasing Behavior.

\subsubsection{Hypothesis3}

Ho3: There is no significant relationship between education and effectiveness of Online Advertisement on Consumer's Purchasing Behavior.

Ha3: There is a significant relationship between education and effectiveness of Online Advertisement on Consumer's Purchasing Behavior.

\subsubsection{Hypothesis 4}

Ho4: There is no significant relationship between occupation and effectiveness of Online Advertisement on Consumer's Purchasing Behavior.

Ha4: There is a significant relationship between occupation and effectiveness of Online Advertisement on Consumer's Purchasing Behavior.

\subsubsection{Hypothesis 5}

Ho5: There is no significant relationship between marital status and effectiveness of Online Advertisement on Consumer's Purchasing Behavior.

Ha5: There is a significant relationship between marital status and effectiveness of Online Advertisement on Consumer's Purchasing Behavior

3.8.6 Hypothesis 6

Ho6: There is no significant relationship between income and effectiveness of Online Advertisement on Consumer's Purchasing Behavior.

Ha6: There is a significant relationship between income and effectiveness of Online Advertisement on Consumer's Purchasing Behavior

\subsubsection{Hypothesis 7}

Ho7: There is no significant relationship between repetitive exposure to Online Advertisement and effectiveness of Online Advertisement on Consumer's Purchasing Behavior.

Ha7: There is a significant relationship between repetitive exposure to Online Advertisement and effectiveness of Online Advertisement on Consumer's Purchasing Behavior.

\subsubsection{Hypothesis 8}

Ho8: There is no significant relationship between time spent in considering Online Advertisement and the effectiveness of Online Advertisement on Consumer's Purchasing Behavior. 
Ha8: There is a significant relationship between time spent in considering Online Advertisement and effectiveness of Online Advertisement on Consumer's Purchasing Behavior.

\section{ANALYSIS \& INTERPRETATION}

TABLE I. Demographic Profile of the Respondents

\begin{tabular}{|l|l|c|c|}
\hline \multirow{1}{*}{ Category } & Count & Percentage (\%) \\
\hline \multirow{5}{*}{ Gender } & Male & 86 & 58 \\
& Female & 64 & 42 \\
\hline \multirow{5}{*}{ Education } & Below 20 years & 64 & 43 \\
& 20-30 years & 36 & 24 \\
& 30- 40 years & 32 & 21 \\
& Above 40 years & 18 & 12 \\
\hline \multirow{5}{*}{ Occupation } & Senior Secondary & 45 & 30 \\
& Graduate & 81 & 54 \\
& Post Graduate & 24 & 16 \\
\hline \multirow{3}{*}{ Marital Status } & Student & 102 & 24 \\
& Service/Employed/Job & 36 & 8 \\
\hline \multirow{3}{*}{ Income } & Self Employed & 12 & 79 \\
& Single & 118 & 21 \\
\hline & Married & 32 & 57 \\
& Less than Rs 20,000 & 85 & 23 \\
& Rs 20,000- Rs 40,000 & 34 & 10 \\
& Rs 40,000- Rs 60,000 & 16 & 10 \\
\hline
\end{tabular}

4.1 HYPOTHESIS TESTING: HYPOTHESIS 1

Ho1: There is no significant relationship between gender and effectiveness of Online Advertisement on Consumer's Purchasing Behavior.

Ha1: There is a significant relationship between gender and effectiveness of Online Advertisement on Consumer's Purchasing Behavior.

TABLE II. Regression Analysis: Impact of Gender on Effectiveness of Online Advertisement Descriptive Statistics

\begin{tabular}{|l|r|r|r|}
\hline & \multicolumn{1}{|c|}{ Mean } & \multicolumn{1}{|c|}{ Std. Deviation } & N \\
\hline $\begin{array}{l}\text { How would you rate overall effectiveness of E- } \\
\text { advertisement on the parameter of 1 to 5? }\end{array}$ & 3.17 & .975 & 150 \\
\hline Gender & 1.38 & .488 & 150 \\
\hline
\end{tabular}


IOSR Journal of Computer Engineering (IOSR-JCE)

Model Summary

\begin{tabular}{|l|r|r|r|r|r|}
\hline Model & R & R Square & \multicolumn{1}{|c|}{$\begin{array}{c}\text { Adjusted R } \\
\text { Square }\end{array}$} & $\begin{array}{c}\text { Std. Error of } \\
\text { the Estimate }\end{array}$ & Sig* \\
\hline 1 & .149 & .022 & .013 & .969 & 0.01 \\
\hline
\end{tabular}

a. Predictors: (Constant), Gender

b. Dependent Variable: How would you rate overall effectiveness of E-advertisement on the parameter of 1 to 5 ?

From table 2, it is clear that there is significant relationship between gender and effectiveness of Online Advertisement on Consumer's Purchasing Behavior. Here the value of $\mathrm{R}^{2}$ is 0.022 which means that $2.2 \%$ of the variance in the effectiveness of Online Advertisement on Consumer's Purchasing Behavior is explained by the gender. Since $\mathrm{p}$ value is significant at $5 \%$ level of significance so the null hypothesis is rejected and the alternative hypothesis is accepted. Thus, there is significant relationship between gender and effectiveness of Online Advertisement on Consumer's Purchasing Behavior.

\subsection{HYPOTHESIS2}

Ho2: There is no significant relationship between age and effectiveness of Online Advertisement on Consumer's Purchasing Behavior.

Ha2: There is a significant relationship between age and effectiveness of Online Advertisement on Consumer's Purchasing Behavior.

Regression Analysis: Impact of Age on effectiveness of Online Advertisement on Consumer's Purchasing Behavior.

TABLE III. Regression Analysis: Impact of Age on the Effectiveness of Online Advertisement

\begin{tabular}{|l|c|r|r|}
\hline \multicolumn{1}{|c|}{ Descriptive Statistics } & Std. Deviation & N \\
\hline How would you rate overall effectiveness of & Mean & & 150 \\
E-advertisement on the parameter of 1 to 5? & & & \\
\hline Age & 1.49 & .739 & 150 \\
\hline
\end{tabular}

Model Summary

\begin{tabular}{|c|c|c|c|c|c|}
\hline Model & $\mathrm{R}$ & R Square & Adjusted R Square & $\begin{array}{c}\text { Std. Error of the } \\
\text { Estimate }\end{array}$ & Sig* \\
\hline 1 & .212 & .045 & .036 & .958 & 0.001 \\
\hline
\end{tabular}

a. Predictors: (Constant), Age

b. Dependent Variable: How would you rate overall effectiveness of E-advertisement on the parameter of 1 to 5 ? 
From table 3, it is clear that there is significant relationship between age and effectiveness of Online Advertisement on Consumer's Purchasing Behavior. Here the value of R2 is 0.045 which means that $4.5 \%$ of the variance in the effectiveness of Online Advertisement on Consumer's Purchasing Behavior is explained by the age. Since $\mathrm{p}$ value is significant at 5\% level of significance so the null hypothesis is rejected and the alternative hypothesis is accepted. Thus, there is significant relationship between age and effectiveness of Online Advertisement on Consumer's Purchasing Behavior.

\subsection{HYPOTHESIS3}

Ho3: There is no significant relationship between education and effectiveness of Online Advertisement on Consumer's Purchasing Behavior.

Ha3: There is a significant relationship between education and effectiveness of Online Advertisement on Consumer's Purchasing Behavior.

TABLE IV. Regression Analysis: Impact of Education on the Effectiveness of Online Advertisement

\begin{tabular}{|l|r|r|r|}
\multicolumn{2}{|c|}{ Descriptive Statistics } \\
\begin{tabular}{|l|r|r|} 
\\
How would you rate overall effectiveness of E- \\
advertisement on the parameter of 1 to 5?
\end{tabular} & Mean & Std. Deviation & N \\
\hline Education & 1.72 & .973 & 150 \\
\hline
\end{tabular}

Model Summary

\begin{tabular}{|c|c|c|c|c|c|}
\hline Model & $\mathrm{R}$ & $\mathrm{R}$ Square & $\begin{array}{c}\text { Adjusted R } \\
\text { Square }\end{array}$ & $\begin{array}{c}\text { Std. Error of } \\
\text { the Estimate }\end{array}$ & Sig* \\
\hline 1 & $.175^{\text {a }}$ & .031 & .022 & .963 & 0.012 \\
\hline
\end{tabular}

a. Predictors: (Constant), Education

b. Dependent Variable: How would you rate overall effectiveness of E-advertisement on the parameter of 1 to 5 ?

From table 4, it is clear that there is significant relationship between education and effectiveness of Online Advertisement on Consumer's Purchasing Behavior. Here the value of $\mathrm{R}^{2}$ is 0.031 which means that $3.1 \%$ of the variance in the effectiveness of Online Advertisement on Consumer's Purchasing Behavior is explained by the education. Since $\mathrm{p}$ value is significant at 5\% level of significance so the null hypothesis is rejected and the alternative hypothesis is accepted. Thus, there is significant relationship between education and effectiveness of Online Advertisement on Consumer's Purchasing Behavior.

\subsection{HYPOTHESIS 4}

Ho4: There is no significant relationship between occupation and effectiveness of Online Advertisement on Consumer's Purchasing Behavior.

Ha4: There is a significant relationship between occupation and effectiveness of Online Advertisement on Consumer's Purchasing Behavior. 
The impact of occupation on effectiveness of online advertisement on consumer's purchasing behavior is shown below:

TABLE V. Regression Analysis: Impact of Occupation on effectiveness of Online Advertisement

Descriptive Statistics

\begin{tabular}{|l|r|r|r|}
\hline & \multicolumn{2}{|c|}{ Mean } & \multicolumn{2}{|c|}{ Std. Deviation } & N \\
\hline $\begin{array}{l}\text { How would you rate overall effectiveness of E- } \\
\text { advertisement on the parameter of 1 to 5? }\end{array}$ & 3.17 & .975 & 150 \\
\hline Occupation & 1.19 & .516 & 150 \\
\hline
\end{tabular}

Model Summary

\begin{tabular}{|c|c|c|c|c|c|}
\hline Model & $\mathrm{R}$ & R Square & Adjusted R Square & $\begin{array}{c}\text { Std. Error of the } \\
\text { Estimate }\end{array}$ & Sig* \\
\hline 1 & .116 & .014 & .004 & .973 & .011 \\
\hline
\end{tabular}

a. Predictors: (Constant), Occupation

b. Dependent Variable: How would you rate overall effectiveness of E-advertisement on the parameter of 1 to 5 ?

From table 5, it is clear that there is significant relationship between occupation and effectiveness of Online Advertisement on Consumer's Purchasing Behavior. Here the value of $\mathrm{R}^{2}$ is 0.014 which means that $1.4 \%$ of the variance in the effectiveness of Online Advertisement on Consumer's Purchasing Behavior is explained by the Occupation. Since $\mathrm{p}$ value is significant at $5 \%$ level of significance so the null hypothesis is rejected and the alternative hypothesis is accepted. Thus, there is significant relationship between occupation and effectiveness of Online Advertisement on Consumer's Purchasing Behavior.

\subsection{HYPOTHESIS 6}

Ho6: There is no significant relationship between income and effectiveness of Online Advertisement on Consumer's Purchasing Behavior.

Ha6: There is a significant relationship between income and effectiveness of Online Advertisement on Consumer's Purchasing Behavior

TABLE VI. Regression Analysis: Impact of Marital Status on Effectiveness of Online Advertisement

Descriptive Statistics

\begin{tabular}{|l|r|r|r|}
\hline & Mean & Std. Deviation & N \\
\hline $\begin{array}{l}\text { How would you rate overall effectiveness of } \\
\text { E-advertisement on the parameter of 1 to 5? }\end{array}$ & 3.17 & & .980 \\
\hline Income & 2.13 & & .277 \\
\hline
\end{tabular}

Model Summary

\begin{tabular}{|l|c|c|c|c|c|}
\hline Model & $\mathrm{R}$ & $\mathrm{R}$ Square & Adjusted R Square & $\begin{array}{c}\text { Std. Error of the } \\
\text { Estimate }\end{array}$ & Sig* \\
\hline 1 & .196 & .084 & .045 & .967 & 0.013 \\
\hline
\end{tabular}


a. Predictors: (Constant), Marital Status

b. Dependent Variable:

How would you rate overall effectiveness of E-advertisement on the parameter of 1 to 5 ?

From table 6, it is clear that there is significant relationship between income and effectiveness of Online Advertisement on Consumer's Purchasing Behavior. Here the value of R2 is 0.084 which means that $8.4 \%$ of the variance in the effectiveness of Online Advertisement on Consumer's Purchasing Behavior is explained by the income. Since $\mathrm{p}$ value is significant at $5 \%$ level of significance so the null hypothesis is rejected and the alternative hypothesis is accepted. Thus, there is significant relationship between income and effectiveness of Online Advertisement on Consumer's Purchasing Behavior.

\subsection{HYPOTHESIS 7}

Ho7: There is no significant relationship between repetitive exposure to Online Advertisement and effectiveness of Online Advertisement on Consumer's Purchasing Behavior.

Ha7: There is a significant relationship between repetitive exposure to Online Advertisement and effectiveness of Online Advertisement on Consumer's Purchasing Behavior.

TABLE VIII. Regression Analysis: Impact of repetitive exposure to Online Advertisement on Effectiveness of Online Advertisement

Descriptive Statistics

\begin{tabular}{|l|r|r|r|}
\hline & Mean & Std. Deviation & N \\
\hline $\begin{array}{l}\text { How would you rate overall effectiveness of } \\
\text { E-advertisement on the parameter of 1 to 5? }\end{array}$ & 3.17 & .975 & 150 \\
\hline $\begin{array}{l}\text { Are you often exposed to Online } \\
\begin{array}{l}\text { Advertisements for major portion of the } \\
\text { day? }\end{array}\end{array}$ & 2.65 & & 1.089 \\
\hline
\end{tabular}

Model Summary

\begin{tabular}{|c|c|c|c|c|c|}
\hline Model & $\mathrm{R}$ & $\mathrm{R}$ Square & Adjusted R Square & $\begin{array}{c}\text { Std. Error of the } \\
\text { Estimate }\end{array}$ & Sig* \\
\hline 1 & .361 & .130 & .122 & .914 & 0.000 \\
\hline
\end{tabular}

a. Predictors: (Constant), Are you often exposed to Online Advertisements for major portion of the day?

b. Dependent Variable: How would you rate overall effectiveness of E-advertisement on the parameter of 1 to 5 ?

From table 8 , it is clear that there is significant relationship between repetitive exposure to Online Advertisement on effectiveness of Online Advertisement on Consumer's Purchasing Behavior. Here the value of $\mathrm{R}^{2}$ is 0.130 which means that $13 \%$ of the variance in the effectiveness of Online Advertisement on Consumer's Purchasing Behavior is explained by the repetitive exposure to Online Advertisement. Since $\mathrm{p}$ value is significant at $5 \%$ level of significance so the null hypothesis is rejected and the alternative hypothesis is accepted. Thus, there is significant relationship between repetitive exposures to Online Advertisement and effectiveness of Online Advertisement on Consumer's Purchasing Behavior.

\subsection{HYPOTHESIS 8}


Ho8: There is no significant relationship between time spent in considering Online Advertisement and the effectiveness of Online Advertisement on Consumer's Purchasing Behavior.

Ha8: There is a significant relationship between time spent in considering Online Advertisement and effectiveness of Online Advertisement on Consumer's Purchasing Behavior.

TABLE IX. Regression Analysis: Impact of time spent in considering Online Advertisement on effectiveness of Online Advertisement

Descriptive Statistics

\begin{tabular}{|l|c|c|c|}
\hline & Mean & Std. Deviation & N \\
\hline $\begin{array}{l}\text { How would you rate overall effectiveness of E- } \\
\text { advertisement on the parameter of 1 to 5? }\end{array}$ & 3.17 & .975 & 150 \\
\hline $\begin{array}{l}\text { Do you spend a large amount of your time in } \\
\text { considering Online advertisement for your purchase? }\end{array}$ & 2.31 & 1.163 & 150 \\
\hline
\end{tabular}

Model Summary

\begin{tabular}{|c|c|c|c|c|c|}
\hline Model & $\mathrm{R}$ & $\mathrm{R}$ Square & Adjusted R Square & $\begin{array}{c}\text { Std. Error of the } \\
\text { Estimate }\end{array}$ & Sig* \\
\hline 1 & $.292^{\mathrm{a}}$ & .085 & .077 & .937 & 0.010 \\
\hline
\end{tabular}

a. Predictors: (Constant), Do you spend a large amount of your time in considering Online advertisement for your purchase?

b. Dependent Variable: How would you rate overall effectiveness of E-advertisement on the parameter of 1 to 5 ?

From table 9, it is clear that there is significant relationship between time spent in considering Online Advertisement and the effectiveness of Online Advertisement on Consumer's Purchasing Behavior. Here the value of $\mathrm{R}^{2}$ is 0.085 which means that $8.5 \%$ of the variance in the effectiveness of Online Advertisement on Consumer's Purchasing Behavior is explained by the time spent in considering Online Advertisement. Since $\mathrm{p}$ value is significant at 5\% level of significance so the null hypothesis is rejected and the alternative hypothesis is accepted. Thus, there is significant relationship between time spent in considering Online Advertisement and effectiveness of Online Advertisement on Consumer's Purchasing Behavior.

Table X. Summary of Hypothesis

\begin{tabular}{|c|c|c|c|}
\hline S. NO. & HYPOTHESIS & NULL HYPOTHESIS & $\begin{array}{c}\text { ALTERNATIVE } \\
\text { HYPOTHESIS }\end{array}$ \\
\hline 1 & Gender & Rejected & Accepted \\
\hline 2 & Age & Rejected & Accepted \\
\hline 3 & Education & Rejected & Accepted \\
\hline 4 & Occupation & Rejected & Accepted \\
\hline 5 & Marital Status & Rejected & \\
\hline
\end{tabular}


IOSR Journal of Computer Engineering (IOSR-JCE)

e-ISSN: 2278-0661, p-ISSN: 2278-8727

\begin{tabular}{|c|c|c|c|}
\hline 6 & Income & Rejected & Accepted \\
\hline 7 & Repetitive Exposure & Rejected & Accepted \\
\hline 8 & Time Spent & Rejected & Accepted \\
\hline
\end{tabular}

\section{CONCLUSION}

With technological advancement being accessible easily, the field of online advertisement and E-Business is definitely going to be the future in the shopping era. In today's world, in which we are living the information is flowing from all sources like television, advertising, films, videos, billboards, magazines, movies, music, newspaper, and internet. Through this research paper, an attempt has been made to find out the impact of certain factors on the Effectiveness of Online Advertisement. From the above research, it can be concluded that factors such as gender, age, education, occupation, marital status, income, repetitive exposure to the Online Advertisement and the time spent on Online Advertisement have significant relationship with the Effectiveness of Online Advertisement.

\section{REFERENCES}

[1] P. Srivastava, "A Study On Impact Of Online Advertising On Consumer Behavior (With Special Reference To E-Mails), International Journal of Engineering and Management sciences, 3(4), 2012, 461-465.

[2] A.B. Mohammed, M. Alkubise, "How do Online Advertisements Affects Consumer Purchasing Intention: Empirical Evidence from a Developing Country, European Journal of Business and Management, 4(7), 2012.

[3] H. Bush, "Advertiser Perceptions of the Internet as a Marketing Communication Tool”, Journal of Advertising Research, 1998, 17-27.

[4] V.P.Nikhil, K. Tiwari and V.Ravikumar, "A study on the Impact of Online Advertisements on Buying Decision of Customers of Passenger Car Industry", Global Illuminators, Proc. Conf. on GIMAR-2015, 1, 128-139.

[5] Rezai, Mohamed, Shamsudin and Zahran, "Effect of Consumer Demographic Factors on Purchasing Herbal Products Online in Malaysia“, 2013.

[6] A. Bhatnagar, S. Misra, and H.R. Rao, "Online risk, convenience, and Internet shopping behavior", Communications of the ACM, 43(11), 2000, 98-105.

[7] A. Bezjizn-Avery, B. Calder, and D. Iacobucci, "New media interactive advertising vs. traditional advertising", Journal of Advertising Research, 1998, 23-32.

[8] Pavlov, A. Paul and W. S. David, "Measuring the Effects and Effectiveness of Interactive Advertising: A Research Agenda", Journal of Interactive Advertising, 11, 2000.

[9] J. Eighmey, "Profiling user responses to commercial Web sites", Journal of Advertising Research, 37(3), 1997, 21-35.

[10] P. Korgaonkar, and L. A. Wolin, "Multivariate analysis of Web usage", Journal of Advertising Research, 39(2), 1999, 53-68.

[11] S. Bhat, M. Bevans and S. Sengupta, “Measuring Users' Web Activity To Evaluate And Enhance Advertising Effectiveness", Journal of Advertising, 31(3), 2002, 97-106.

[12] https://www.academia.edu/7809876/The_Impact_of_Advertising_on_Consumer_Purchase_Decision._A_Study_of_GIJ_Students_

[13] http://www.diva-portal.org/smash/get/diva2:325368/FULLTEXT01.pdf 